\title{
AS PARTES DO JOGO
}

\author{
POR \\ BERTA WALDMAN/ALCIR PÉCORA \\ Universidade de São Paulo, Campinas
}

Nada lembra tanto um buraco como tima saliência.

SAINTE-Beuve

E sempre bom lembrar que um cope vazio está cheio de ar.

GILBERTo GiL

\section{PRimEIRAS REgRAS}

Dentro os textos que compõem As Marcas do Real ${ }^{1}$, livro de estréia de Modesto Carone na ficção, escolheu-se «O jogo das partes» como objeto particular desta análise porque pareceu enfeixar, de modo explícito, o conjunto dos elementos discursivos que vão sendo dispostos e trabalhados ao longo de toda a obra. Deter-se nesse conto, portanto, responde a um interesse mais ambicioso, qual seja, o de procurar discernir o jogo de significações peculiares a As Marcas do Real, especialmente no que se refere ao seu modo de enunciação e envolvimento do leitor.

Eis o conto:

\section{O JOGO DAS PARTES 2}

Quando o pano-de-boca de teatrinho subiu, senti os joelhos tremerem. Olhei en volta, mas a escuridão velava os rostos; de vez em quando um facho de luz iluminava uma fileira de dentes. Essa circunstância aumentava minha ansiedade, pois suprimia os pontos de referência mais próximos. Só me acalmei ao apalpar o tambor do re-

${ }^{1}$ As Marcas do Real, de Modesto Carone (Rio de Janeiro: Paz e Terra, 1979).

2. «O jogo das partes», pp. 103-107. 
vólver no bolso: o aço gelado abria uma clareira na confusão. Mesmo assim não consegui desviar a vista do palco: os efeitos sonoros já pontuavam a chuva nos vidros da janela pintada.

Realmente eu estava inquieto: o quadro porém era simples: entrando pela porta da direita, tateava até a mesa sem dizer uma palavra -apenas monossílabos em cima do tapete. Ao chegar ao centro, acendia o castiçal e segurava-o na altura do peito. Num rápido movimento de pescoço notava que os sussurros ecoavam na quina da quarta parede; caminhava aflito para o foco invisível, a peruca balançando no ritmo do corpo. Enquanto isso a tormenta engrossava; uma sequência de relâmpagos atraía meu olhar para o espelho oval de cenário de papelấo e nesse inatante eu via os lábios descarnados de Olímpia. O jogo de luzes era precário, mas eu recuava repetindo várias veces a palavra não; no climax, a cortina baixava ao som de trovões distantes.

A cena curta sustentava o suspense da peça; o público aplaudia com estardalhaço antes que o pano tocasse o chão. No entanto nada me tranquilizava: ao tomar o ônibus para o subúrbio eu invariavelmente transpirava muito. Isse não significa que estivesse à vontade naquela noite; com efeito, ao subir a escadinha da platéia tropecei nos degraus de madeira e rolei em cima do revólver; minha sorte foi ter travado o gatilho antes de sair de casa.

Nao preciso dizer que meu coração estava aos pulos ao me sentar entre os espectadores: não enxergava coisa alguma pela frente. Isso explica o tremor nos joelhos e a necessidade de calma; sabia porém que a sala estava cheia e que a função começava.

Apesar de tudo não hesitei em me levantar na hora certa e abrir caminho da fila onde estava até o poço da orquestra; nesse ínterim já tinha acendido o castiçal e me preparava para ir à ponta do palco. Ao estacar diante do espelho oval, saquei a arma e visei a cabeça; no terceiro não, disparei. $\mathrm{O}$ tiro foi quase à queima-roupa e a bala perfurou o rosto embaixo do olho; assim que caí no tapete, voltei à poltrona.

Tenho a impressão de que no primeiro momento ninguém disse nada; talvez confundissem o que estava acontecendo com o enredo da peça; ao gritar de dor no palco, veio o pânico e as luzes se acenderam. Ainda entorpecido, eu via as pessoas correndo; as que ficavam sentadas também não escondiam o medo. Seja como for, eu continuava indiferente ao tumulto; com a nunca apoiada no espaldarda poltrona, espiava o sangue escorrer do olho para a boca como uma lágrima perdida.

Inicialmente, considerando-se a ocorrência da palavra jogo, no contexto do título, pode-se notar que ela aponta menos para acontecimentos, cujas regras se reconhecen prontamente, e cuja harmonia é dada pela pessoalidade do desempenho do jogador, do que para a própria concepção de jogo. Pode-se dizer, nesse sentido, que o título anuncia menos a reali- 
zação de uma partida, do que uma chamada para as condições de sua realização.

Nessa mesma linha de raciocínio, seria possível reconhecer aí uma tautologia, já que todos os jogos supõem partes, tais como etapas, peças, virtuais jogadores, etc. Essa consideração, no entanto, implicaria em se interpretar o título como tendo o sentido de «jogo feito de partes», e isto significaria descaracterizar o aspecto ativo das partes na constituição do jogo, o que representa uma leitura viável da expressão jogo das partes. Reconhecido isto, a tautologia se desfaz; as partes já não se referem apenas a um quadro apriorístico que define o jogo enquanto tal e o configuram como uma totalidade, mas à própria efetivação do jogo: as partes jogam.

Dito de outra forma, a atribuição de um jogo às partes significa que permanecem solitárias, aquém da referência a um possível elemento comum externo à sua própria parcialidade. Confinadas em si mesmas, cristalizam-se.

Há nesse movimento de cristalização das partes alguma proximidade com a idéia de alegoria, tal como é formulada por Walter Benjamin, em que os fragmentos se acumulam sem visar a uma clara finalidade. Ainda segundo Benjamin, tais fragmentos são regidos pela melancolia; não aquela que reflete a nostalgia pela totalidade perdida, mas a que reconhece a impossibilidade histórica dessa mesma totalidade. Nesse sentido, o título anunciaria o relato de um processo irreparável de assimilação dos próprios limites e da sua opacidade em relação a si, aos seus, aos céus.

Entretanto, a noção de jogo, no contexto da alegoria, parece traçar uma ambigüidade quanto às diferentes posturas que envolvem a um e a outro: à melancolia se contrapõe o lúdico, o qual se acentua na citação que o título faz de uma peça de Luigi Pirandello, «Il giuoco delle parti».

\section{JOGOS DESDOBRÁVEIS}

A história que o texto conta é a de um homem que, inquieto, toma o ônibus do subúrbio em direção ao teatro. O pano-de-boca sobe e tem início a função. Por um instante, ele observa os demais espectadores, mas não consegue distinguilos na escuridão da platéia. $\mathrm{Na}$ cena, um ator caminha até o centro do palco e acende um castiçal, depois prossegue até um espelho oval em que se reflete uma visão que o faz recuar, repetindo várias vezes a palavra não. E aí termina a cena. Enquanto o público aplaude, o homem sobe ao palco e, à queima roupa, dispara um tiro que atinge o rosto do ator. Em meio ao tumulto criado, retorna ao seu lugar de observador na platéia. 
É ainda a história de um ator que, no momento em que o pano-deboca do teatro sobe, observa inquieto, da coxia, a platéia e o palco que os separa. Não consegue distinguir senão vultos na escuridão. Esparsos fachos de luz dificultam-lhe inclusive conhecer exatamente a localização do palco. Em seguida, entra ou imagina entrar em cena, perfazendo os passos de uma prévia marcação: caminha até o centro do palco, acende um castiçal, prossegue até un espelho oval, onde se reflete uma visão que o faz recuar, repetindo continuadas vezes a palavra não. $\mathrm{E}$ aí termina a cena. Mais tarde, ao ir para casa, ainda permanece inquieto. Certa noite, no momento final da marcação em que o ator se depara com o espelho e repete a palavra usual, quando já principiam os aplausos, um homem levanta-se da platéia, sobe as escadas, invade o palco e dispara um tiro que atinge o rosto do ator. Em meio ao tumulto criado, retorna ao seu lugar de observador na platéia.

E também a história de um homem que, inquieto, toma o ônibus para o subúrbio, em direção ao teatro. Subindo as escadas, chega à platéia e senta-se entre os espectadores. O pano-de-boca sobe e tem início a função. Por um instante, ele observa os demais espectadores, mas não consague distingui-los na escuridão. Concomitantemente, o mesmo homem, um ator, observa inquieto, da coxia, a platéia e o palco que os separa. Não consegue distinguir senão vultos na escuridão. Esparsos fachos de luz dificultam-lhe inclusive conhecer exatamente a localização do palco. Entra ou imagina entrar, enquanto se observa entrando em cena, perfazendo os passos de uma prévia marcação: caminha, observa-se caminhar, até o centro do palco, acende, vê acender o castiçal, prossegue até o espelho oval. Aí, o mesmo homem, vindo da platéia e subindo os degraus em direção ao palco, quando profere o terceiro não, dispara um tiro que $o$ atinge no rosto. $\mathrm{O}$ ator cai sobre o tapete ao tempo em que o mesmo retorna ao seu lugar de observador na platéia.

E é á história de uma primeira pessoa, a qual se lembra de quando viu o pano-de-boca do teatrinho subir. Lembra-se também que não estava na platéia ou na coxia, estando provavelmente ora em um, ora em outro, ou em ambos, ou mesmo em nenhum desses lugares. Nem por isso reconhece existir alguma confusão em sua lembrança, considerando o quadro bastante simples. Lembra-se tranqüilamente de ter se sentido inquieto. E mantém a mesma calma quando se lembra não apenas de ter sido assassinado ou de assassinar, mas de ter disparado um tiro e de ter sido atingido por ele no rosto. Finalmente, lembra-se de ter retornado ao seu lugar na platéia e observado o sangue escorrer do seu ferimento.

Mas também é outra história. 


\section{O JOGO QUE PERDE O SUJEITO}

Observando-se o uso da primeira pessoa no texto, dificilmente poderse-ia interpretá-lo como uma referência ao único, ao unívoco, à identidade. Tomando-se, por exemplo, o seguinte trecho,

... entrando pela porta da direita, tateava até a mesa sem dizer uma palavra...,

que aparece no início da narrativa e que é antecedido pela frase,

Realmente eu estava inquieto...,

pode parecer a uma leitura inicial que se atribuem as ações de entrar, tatear e dizer a um eu singular, anteriormente determinado. No entanto, esse $e u$ parecia demarcar alguém que ocupa um lugar na platéia:

Olhei em volta, mas a escuridão velava os rostos...,

Não consegui desviar a vista do palco..., etc.

Ordinariamente, o escuro, durante uma representação, recobre o que é platéia. Ao contrário; as ações dos verbos grifados contêm índices de uma marcação de cena e, portanto, supõem um sujeito ator.

Para manter a expectativa de que o eu se localiza na platéia, pode-se tentar interpretar essas ações como sendo atribuiç̧óes a um ele, uma vez que, tal como foram empregados, os verbos não guardam marcas distintivas em relação à primeira e terceira pessoa. Nesse sentido, ler-se-ia assim a sequiência dessas ações:

(eu via da platéia que) ele acendia o castiçal..., ele segurava..., ele notava..., ele caminhava...,

mas, a seqüência se completa com uma atribuição explícita ao eu:

... eu via...

Ou seja, ainda que essa expectativa se mantenha durante um certo tempo de leitura, o desenvolvimento narrativo resgata a ambigüidade indiciada a partir do confronto daquelas ações que pareciam delimitar claramente a platéia, com aquelas, sem marcas pronominais distintivas, mas características do espaço cênico. 
Nesse momento, o que de imediato ocorre, é a hipótese de um desdobramento do sujeito no interior de um projeto de ubiquiidade. Tipicamente intervêm aí categorias metafísicas e psicanalíticas de interpretação, onde por diferentes vias apresenta-se a questão da realidade, de um lado, e a questão da identidade, de outro, a partir de um princípio de alteridade.

Mas, não se vai por aí. Se se estiver atento à estratégia discursiva mobilizada pelo texto, vale dizer, à atuação dos interlocutores entre os seus possíveis sentidos, verifica-se que o processo de envolvimento do sujeito por dois espaços distintos (palco/platéia) não se faz sem prejuízo para a sua caracterização como primeira pessoa. $O$ modo particular da narração não fornece à leitura, de imediato, elementos para que se reconheça o eu como parte constitutiva de ambos os lugares.

Como se viu, logo no início, o que se faz é criar uma determinada expectativa que posteriormente é rompida. Ainda mais: é rompida não por uma determinação explicitamente contrária, mas pela ambigüização do sujeito. O seu princípio de desdobramento, portanto, caracteriza-se pela passagem das ações de um espaço a outro, enquanto o eu obscurece. As ações não se engatam a ele, predicam primeiramente a ausência. $O$ agente dos processos é apenas virtualidade.

Neste ponto, poderiam intervir categorias ideológicas; esse movimento de apagamento das diferenças entre o eu e o ele, do que resulta uma suspensão do sujeito em relação aos processos atribuíveis a si, poderia ser recoberto por uma interpretação crítica em que a ação é estranha à pessoalidade, ou, de maneira mais geral, em que o processo histórico se faz apesar do sujeito e contra ele, na medida em que o descaracteriza enquanto agente e dilui a sua especificidade. A direção geral do processo seria a de reificação de antagonismos, etc.

No entanto, esse movimento de diluição do sujeito ganha novos atributos e radicaliza-se com a observação da maneira pela qual a narração dispõe os espaços de atuação subjetiva.

\section{Espaços iLIMITAdos}

Até o momento, tratou-se de palco e platéia como se os limites entre ambos fossem perfeitamente nítidos. Tome-se, porém, a primeira frase da narrativa: «Quando o pano-de-boca do teatrinho subiu, senti os joelhos tremerem.» A expectativa criada por ela, jogando com o seu contexto usual de emprego, é a de que alguém, da platéia, assiste a uma representação. No entanto, não há nenhuma determinação explícita da posição desse sujeito em relação àquilo que vê. É perfeitamente plausível, como 
prevê uma das histórias, que alguém, da coxia, do interior do palco, portanto, observe a subida do pano-de-boca. A cena, desse ponto de vista, é o avesso da anterior. Aí, o foco da visão não é o palco, mas a platéia. Se se quiser, é possível ler essa inversão como uma atribuição à platéia do estatuto de palco.

A diluição, agora, dá-se entre os próprios pólos da representação. E o jogo de construir-se uma expectativa para rompê-la posteriormente é mantido pela narração, quanto mais pelo fato de referir-se continuamente àquilo que se chamou foco de visão, como se estivesse claramente demarcado: «Olhei em volta..., o quadro era simples..., ao chegar ao centro..., foco invisível...», etc. Pelo que se notou, há uma expansão do espaço dada pela ruptura de seus limites originais, de tal modo que palco pode englobar platéia ao mesmo tempo em que deixa de ser palco. A diluição dos limites resulta na descaracterização objetiva dos espaços. Claramente, na frase "O quadro, porém, era simples», a noção de quadro, a partir da ausência de referências anteriores e a ambigüidade do sujeito, designa uma totalidade indeterminada: palco?, platéia?, ambos? Nenhum dos dois?

Ou seja, as ações percebidas como desvinculadas do sujeito, também o são na relação com o espaço. Palco e platéia são categorias que oscilam em função do ponto-de-vista do sujeito e, como este não se revela, permanecem virtualidade, possíveis partes.

\section{IMAGENS NO ESPELHO}

A análise da narração até a visão de Olímpia descreveu sucessivos movimentos de desdobramento que, criando e rompendo expectativas de leitura, tendiam não à duplicação das partes, mas a um certo desregramento entre elas, a uma diluição de seus nexos. Os limites do eu e do outro, do palco e da platéia adquirem um contorno cada vez mais vicário.

Atentando, agora, para as ações que se sucedem à visão do espelho, pode-se reconhecer um novo sentido para o apagamento e a desintegração que se configuram até esse momento. Exemplarmente, no que se refere às atribuições ao $\mathrm{eu}$, a figura de Olímpia detona um processo nitidamente reflexivo.

Se na primeira parte do conto existe uma suspensão gradual dos nexos, de tal forma que o conjunto não se configura organicamente, o espelho surge para direcionar as partes contra si mesmas, para instituir em cada uma delas o seu avesso, o seu antagonista.

Nesse jogo, cada movimento representa igualmente um contramovimento, como lê a terceira história. O que antes era desmembramento, 
organiza-se agora como reflexo. A repartição aleatória do sujeito configura-se numa duplicidade de faces apostas e reversíveis de um mesmo traço. Assim, sobe-se a escada do palco para a platéia, ou sobe-se da platéia para o palco; vai-se do teatro para o subúrbio, ou vai-se para o teatro no subúrbio; senta-se na platéia ou atua-se no palco; dá-se ou recebe-se um tiro... É o caso de se lembrar de Poe ou de Hoffmann, mas principalmente de Escher.

Cada um dos espaços virtualmente pode ser outro, mas ao se configurar como autro tende a anular a memória do primeiro; portanto, o desdobramento nunca é aditivo; e tampouco é alternativo, uma vez que o reconhecimento de uma das partes supõe uma escolha provisória: como se viu na análise da sequiência verbal da marcação de cena, nenhuma escolha se sustenta indefinidamente.

Dessa forma, questiona-se a todo momento o ponto de vista da leitura, realizando na interlocução do texto a percepção fragmentária do eu do enunciado,

... senti os joelhos... iluminava uma fileira de dentes... eu via os lábios descarnados... visei a cabeça... perfurou o rosto embaixo do elho...,

a qual, por sua vez, é homóloga à fragmentação do processo narrativo, onde, como se ressaltou, as ações desligam-se do sujeito. Ou seja, as escolhas interpretativas a que é conduzido o leitor atualizam o estatuto de fragmento evidente no enunciado. Partem o leitor.

\section{LINGUAGEM EM FÉRIAS}

No entanto nada me tranquilizava: ao tomar o ônibus para o subúrbio eu invariavelmente transpirava muito. Isso não significa que estivesse à vontade naquela noite...

Observando-se o primeiro periodo do trecho acima, entende-se obviamente que a situação emocional do sujeito é de intranquiilidade e de tensão. Já a frase seguinte, enuncia que aquile que ficou dito antes não deve ser entendido como um indício de que o sujeito estava à vontade e, portanto, tranqüilo. Ocorre que não existe absolutamente nada na primeira afrrmação que pudesse suscitar essa interpretação; afinal, ela diz em excelente portiguês exatamente o contrário disso. Está perfeitamente claro que, se nada tranqüilizava, então não se estava tranqüilo. A pergunta agora é 
pelo sentido desse trecho, o qual, aliás, retoma um tipo de relação recorrente em quase todos os períodos do comto.

Inicialmente, poderia parecer que uma sequiência elaborada dessa forma fosse apenas redundante: a segunda parte repete a primeira. No entanto, se é verdade que as afirmações são idênticas, cumpre observar também que a segunda é construída negativamente em relação à anterior. Ou seja, estabelece uma oposição entre informações semelhantes. Isso deve adiantar algo quanto à reflexividade das ações; cada uma delas é relacionada à anterior não pelo que significa, mas pelo que nega. $O$ fundamento do nexo deste discurso é o não. $\overrightarrow{\mathrm{E}}$ ele que está subjacente à utilização que o texto faz dos relatores constatativos, concessivos, adversativos, e das construções anafóricas de cunho explicativo: cada nova forma virtual de coesão apenas não é redundante porque o seu relacionamento se faz através de uma atribuição falsa ao processo anterior. Diz-se o mesmo, como se o afirmado anteriormente levasse a supor o contrário.

Ou seja, pode-se dizer que existe um desenvolvimento discursivo apenas no sentido de que a cada momento anula-se o seu passado. Cada frase é um reflexo no espelho da anterior. Daí que o discurso explicativo, hierarquizado, subordinado, que indicia a profusão dos relatores apontados, não é senão um simulacro de organização. Ou melhor, esse discurso constrói a impossibilidade de se operar qualquer desdobramento positivo. Nesse sentido, fracassam todas as tentativas de se interpretar o eu como um sujeito ubíquo: ele não pode duplicar-se, mas apenas instituir-se como seu adversário.

Se se quiser pensar esse discurso nos termos de uma teoria da enunciação, ter-se-ia que verificar, por um lado, uma continua dispersão dos elementos colocados em jogo pelo enunciado, e, por outro, uma tentativa de dispor os fragmentos resultantes em uma enunciação coesa, cujo efeito de sentido é a anulação das partes que se sucedem. A virtual ordem da enunciação não conduz a uma reintegração, ao estabelecimento de vínculos sólidos entre o eu, o outro, suas ações, seus lugares (e, certamente, o tempo dessas partes), e sim à criação de uma ilusão, no sentido de que a enunciação procede como se realmente estivesse operando a totalidade. As ações desencontradas, o dilaceramento do sujeito, a sua suspensão em vista dos acontecimentos, todos os índices de ruínas que se pode observar, tudo é tratado como objeto de discurso racional, como um quadro clínico onde a emoção, a empatia não têm lugar. Não parece necessário estender-se esta reflexão, para que se reconheça aí um discurso crítico em relação à forma de representação intelectual que ae configurar seu objeto perde de vista a sua original vitalidade, a qual apenas se mantém no conjunto das atividades a que está interligada a linguagem, no sprach- 
spiel referido por Wittgenstein. Fora daí, quando a linguagem entra em férias, o seu falar já não é parte de uma forma de vida, mas o testemunho de uma doença, de uma armadilha em que sucumbiu o sujeito.

Nessa linha de raciocínio, o jogo das partes não tem a grandeza, o gesto supremo, de um jogo de vida ou morte: é um jogo de mortos. E afinal, se o eu é enunciado como um ele, uma nãopessca, incapaz de contarse a si mesmo, então o lugar de sujeito de discurso é ocupado por um discurso pronto, acabado, cristalizado. Portanto, um anti-discurso, em que a linguagem é subtraída da relação com as circunstâncias múltiplas e irredutíveis na qual adquire sentido e responde à experiência e à pessoalidade do sujeito. Presa de um arcabouço que the foi legado, a enunciação imprime ao enunciado uma marca que lhe é estranha e indiferente, diluindo assim o vínculo do eu consigo mesmo e com os acontecimentos que vivencia.

Aliás, a vivência não tem lugar neste tipo de discurso, que se constitui como uma barreira entre a virtualidade do sujeito de jogar abertamente com a linguagem e as coisas, de significar sua existência, e a práxis diária do jogo. Ou seja, o eu mobiliza um discurso que o exclui: ao colocar ordem na casa, é posto na rua.

O trabalho de Modesto Carone incide criticamente sobre essa linguagem em férias que, em última instância, reduz o sujeito a receptáculo de verdades ou categorias exemplares e definitivas, particularmente quando sistematizam-se em um falso discurso do conhecimento, de si e da história. $O$ gesto criado pelo conjunto de seus textos aponta para a distância entre as regras e a experiencia, expondo assim os mecanismos de poder subjacente ao tratamento da realidade que transfere as suas marcas ao antidiscurso. E então, de que lugar se conta?

\section{ERrata}

Para repetir Wittgenstein, em suas Investigações Filosóficas, ele se refere a jogos de linguagens como processos lingüisticos que mobilizam diferentes atitudes do sujeito nas múltiplas situações que vive e se envolve. Numa obra literária, para que o jogo de linguagem tenha a propriedade reveladora, de alcance ontológico, é necessário que a linguagem, sobre ser o material da ficção, constitua também, de certo modo, o seu objeto.

Tal ocorre com os contos de Modesto Carone. Em todos eles, observase uma relação essencial entre a ação narrada e o jogo de linguagem que, conforme a análise de «O jogo das partes», envereda por um duplo ca- 
minho. De um lado, a construção fragmentária de linguagem responsável pela liberação do sujeito e das ações que pairam suspensas, isentas de um agente acionador que por elas se responsabilize; libertas ainda de um espaço que se torna reversível, à mercê de um ponto de vista que viaje pelos intervalos do texto com a sua perspectiva e o seu ângulo de visão. De outro lado, a linguagem vista a partir da enunciação que, ao criar nexos sobre as partes que são desconexas, atua como se estivesse frente a um universo não problemático; tudo se passa como se houvesse uma harmonia dada entre o pensamento preciso representado pela enunciação e o universo fantasmagórico revelado no enunciado.

Ao se estilhaçar, a linguagem conta ela mesma a perda da visão de conjunto do indivíduo, tornando-se homóloga à fragmentação da experiência, onde justamente falta o sentido pela ausência dos nexos que retomariam a multiplicidade das coisas na coerência do sistema. Daí a possibilidade de as partes permutarem, tornarem-se reversíveis, como «peças de um caleidoscópio», as quais retornam sempre para compor, em um universo nítido e poroso, ao mesmo tempo, imagens diferentes que, entretanto, guardam a lembrança que a semelhança das partes institui.

Bem visto, tudo em As Marcas do Real se reduz à parte: o inimigo ("As faces do inimigo») são os pelos do narrador que crescem à sua revelia; uma farda sem pescoço é a imagem vista pela personagem de «Choro de Campanha»; em «Mabuse», o narrador se conta como objeto da visão de um olho que o espia. Mais nitidamente partes reflexas e antagônicas, como em «O jogo das partes», aparecem em «Pista dupla», onde o narrador é provido de duas caras - uma faz o que a outra repele; «Beco das flores», onde um narrador ou dois narradores em primeira pessoa compõem o espelhamento de ações que culminam na morte do homem que se assiste sendo morto.

O amor extenuado, o homem desfibrado, o filho parricida, a mãe/ mulher castradora, a violência que se volta para o seu agente, a transmutação do corpo pelo estranhamento de suas extremidades, têm no desmembramento da linguagem o seu reflexo.

Mas a mesma linguagem que se golpeia para afinar a sua expressividade, arma-se de uma unidade pré-construída que se descaracteriza enquanto fala de um sujeito de experiência individualizada. Trata-se ainda da perda, mas ilusória e ironicamente tratada como se não o fôra.

No limiar de uma e de outra, como o «Angelus Novus» de Paul Klee referido por Benjamin, em que o anjo tem o rosto voltado para o passado em ruina, ao mesmo tempo em que uma tempestade -o progressoempurra-o para o futuro, os contos de Modesto Carone, ao mesmo tempo que referem ao estilhaçamento da vida coletiva, à fragmentação da expe- 
riência individual, contando nesse sentido uma história descontínua, contraditória, etc., remetem também a uma concepção de história que lhe é inteiramente oposta, desta vez, linear, ordenada e para além do indivíduo. É por aí, no plano da construção linguística, que autor mostra a história do autoritarismo, da burocratização do cotidiano, do confinamento da percepção e outros processos dessemelhantes. Da tensão entre ambas, da distância que estabelece com o narrado, resulta o clima noturno dos contos que têm em Poe, Kafka e Brecht interlocutores obrigatórios. Concomitantemente, a atração pelo lúdico, além de transformar o leitor no parceiro deste jogo quebrado, absorve-o como lance, parte da atmosfera onírica, fantasmagórica, regida pela ambigüidade. Aqui, o sentido não resvala para outro sentido, mas é antes o outro de todo sentido. Ou, todo sentido é aparência, capote do vazio. 